\title{
Upper Airway Changes after Maxillary Distraction Osteogenesis in Cleft Lip and Palate Patients
}

\author{
S. Abuzinada*, A. Alyamani \\ Oral and Maxillofacial Surgery Department, King Abdulaziz University, Jeddah, Saudi Arabia \\ Email: sondoz@hotmail.com
}

Received 14 November 2015; accepted 19 January 2016; published 22 January 2016

Copyright (C) 2016 by authors and Scientific Research Publishing Inc.

This work is licensed under the Creative Commons Attribution International License (CC BY). http://creativecommons.org/licenses/by/4.0/

(c) (i) Open Access

\begin{abstract}
Purpose: To measure the upper airway changes associated with maxillary distraction osteogenesis in cleft lip and palate patients in the immediate post operative period and 12 months later. Materials and Methods: Seven patients with repaired cleft lip and palate (CLP) presented with severe maxillary hypoplasia. They were examined initially at T1 predistraction phase. Records taken included radiographs (orthopantograms OPG, lateral cephalometric, posteroanterior). Cephalometric analysis was done to evaluate the upper airway. Mean age is 17 years and the reverse overjet > $6 \mathrm{~mm}$. They underwent maxillary Le Fort I distraction using external rigid distracters (RED). Cephalometric analysis to evaluate the upper airway was repeated at the end of the consolidation phase T2 and twelve months after distractor removal T3. Results: The range of maxillary advancement was between $8-15 \mathrm{~mm}$ (mean $9 \mathrm{~mm}$ ). The anteroposterior distance of the superior velopharynx (PPS) and middle velopharynx (SPPS) increased at T2. A small amount of reduction in these values was recorded at T3. The inferior velopharynx (MPS) and the oropharynx (IPS, EPS) showed minimum increase in anteroposterior distance in only two patients at $\mathrm{T} 2$ and no change at T3. Conclusion: All seven patients showed clinical improvement in the upper airway and an increase in the upper airway values on lateral cephalometric radiographs.
\end{abstract}

\section{Keywords}

Cleft Lip and Palate, Maxillary Hypoplasia, Distraction Osteogenesis, Upper Airway

\footnotetext{
${ }^{*}$ Corresponding author.
} 


\section{Introduction}

Cleft lip and palate patients usually present with a challenging midface hypoplasia that creates both esthetic and functional problems in addition to a compromised upper airway. The severe scaring from previous surgeries restricts the maxillary growth and adds more insult to injury, making this condition a more complex one to manage. In the past, the standard Le Fort I advancement was the treatment of choice. However, with the emergence of Distraction Osteogenesis (DO) and its application in the orofacail region, a new diversion was created. DO has been widely used to advance the midface region in subjects with severe maxillary deficiency using the External Rigid Distractor (RED) [1].

The advantages of DO are numerous, including the ability of the soft tissues to gradually remodel and adapt to the underlying bony advancement. This is a great advantage in cleft lip and palate patients who present with severe palatal scaring and require large maxillary advancements. For this reason surgeons applied distraction osteogenesis methods on cleft lip and palate patients and reported the effectiveness of distraction on function and esthetics [2]. Another major advantage of DO is that it makes large maxillary advancements possible which produces a noticeable increase in the upper airway structures and a reduction in airway resistance. Many studies on airway changes after maxillary distraction osteogenesis in cleft lip and palate patients have been reported in the literature [3] [4]. It has been noted that when maxillary distraction osteogenesis was used to advance the maxilla in cleft lip and palate patients, the greater the amount of maxillary advancement the greater the changes and enlargement in the upper airway structure with a reduction in airway resistance. With maxillary distraction a larger advancement is achieved, therefore, more changes are noted in maxillary skeletal position, soft palate position and pharyngeal airway size. These dramatic changes show better stability than conventional Le Fort I advancement [3] [5] [6].

The aim of this retrospective study was to measure the upper airway changes that occurred with maxillary distraction osteogenesis in cleft lip and palate patients in the immediate post operative period and 12 months later.

\section{Patients and Methods}

In this study we included seven cleft lip and palate patients (CLP) with severe maxillary hypoplasia and a reverese overjet $(>6 \mathrm{~mm})$. They were all evaluated and treated at the oral-maxillofacial surgery clinic between 2007-2011. Four patients had bilateral CLP and three had unilateral CLP. Their ages ranged between (16 - 21) mean age 18.2 years. Clinical examination revealed severe maxillary hypoplasia with a class III dental malocclusion and reverse overjet. All patients had normal mandibular growth and development according to cephalometric records. They all underwent surgical repair of the cleft lip and palate during the first two years of life. This was followed by surgical repair of the alveolar cleft using iliac bone graft at variable ages ranging between 11 - 14 years.

Initial records were obtained at T1 including clinical picture and radiographs (orthopantograms OPG, lateral cephalometric, posteroanterior).

All seven patients had an occlusal discrepancy of $6 \mathrm{~mm}$ and more due to the hypoplastic maxilla. Under general anesthesia and oral intubation. All Patients with a velopharyngeal flap were intubated successfully using fiberoptic intubation and the flap was left intact. A high Le Fort I osteotomy was performed and the maxilla was down fractured fixed to the RED (KLS Martin, Tuttlingen, Germany) using $2 \mathrm{~mm}$ plates and screws. After a 7day latency period the distractor was activated at a rate of $1 \mathrm{~mm}$ per day in 2 rhythms. When the desired amount of maxillary advancement was achieved with an adequate occlusal overjet, the distraction was discontinued . After completing a three month consolidation period a second set of cephalometric records were obtained T2 and the distractor was removed followed by a close postoperative follow up period. During the postoperative follow up a third set of cephalometric records were obtained after a twelve month follow up period T3 (Figure 1(a), Figure 1(b)).

\section{Cephalometric Evaluation}

We used the most commonly used landmarks in orthodontic analysis to assess upper airway changes following the evaluation methods used by Mochida et al. [3] as shown in (Figure 1(a)). The palatal pharyngeal space (PPS) is the anteroposterior depth of the pharynx measured between the posterior pharyngeal wall and the posterior nasal spine (PNS) on a line parallel to the Frankfurt Horizontal (FH) plane that runs through the PNS. The superior 

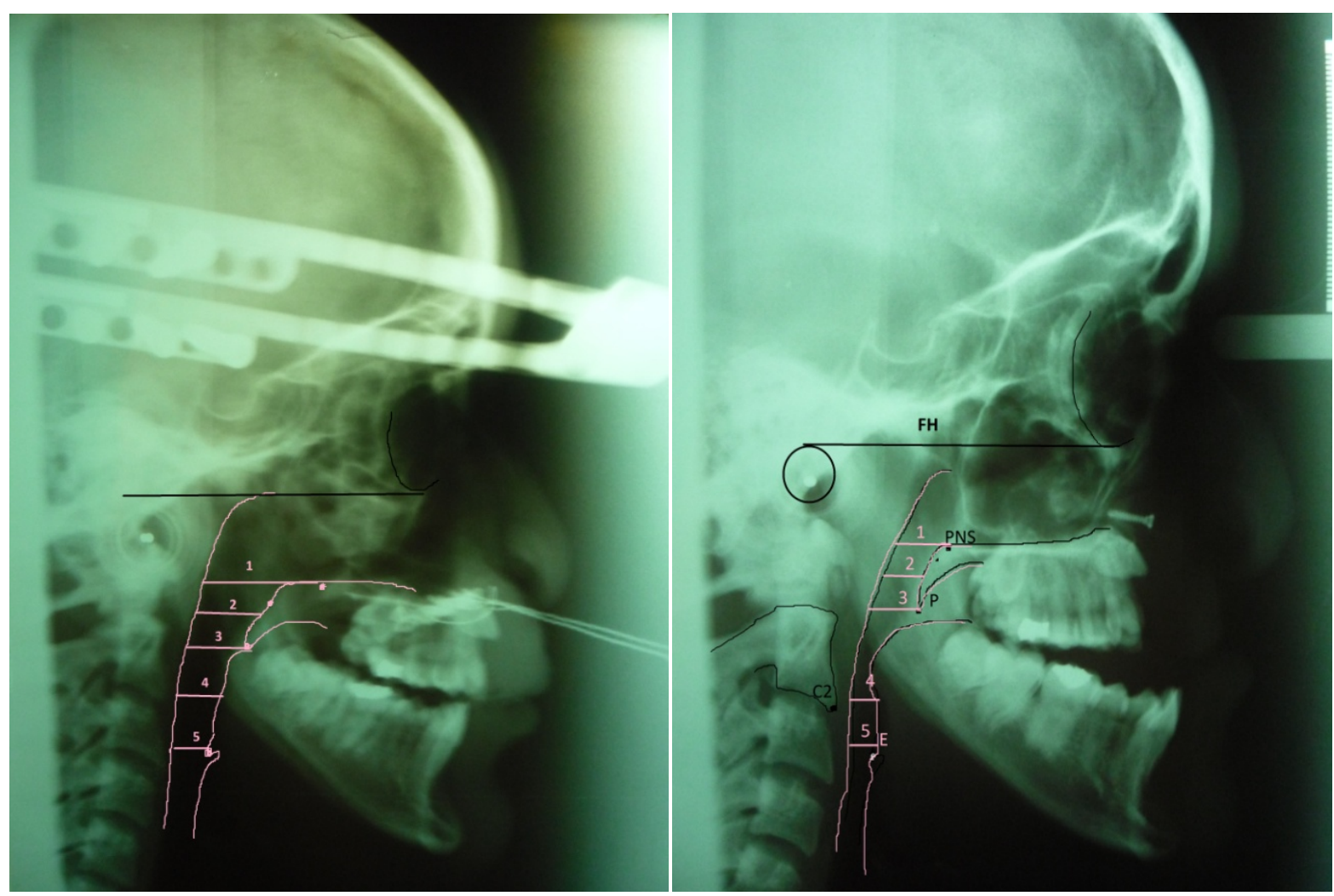

Figure 1. (a) Cephalometric evaluation for upper airway before maxillary Le Fort I distraction osteogenesis; (b) Cepha- lometric evaluation of upper airway at the end of distraction . "PNS: Posterior Nasal Spine, P: tip of soft palate, E: Tip of epiglottis, C2; inferior point of C2 1: PPS, palatal pharyngeal space 2: SPPS, superior posterior pharyngeal space. 3: MPS, middle pharyngeal space. 4: IPS, inferior pharyngeal space [3].

posterior pharyngeal space (SPPS) is the anteroposterior depth of the pharynx measured between the posterior pharyngeal wall and the dorsum of the soft palate on a line parallel to the FH plane that runs through the middle of the line from the PNS to the tip of the soft palate (P). The middle pharyngeal space (MPS) is the anteroposterior depth of the pharynx measured between the posterior pharyngeal wall and the dorsum of the tongue on a line parallel to the FH plane that runs through P. The inferior pharyngeal space (IPS) is the anteroposterior depth of the pharynx measured between the posterior pharyngeal wall and the surface of the tongue on a line parallel to the FH plane that runs through C2. The epiglottic pharyngeal space (EPS) is the anteroposterior depth of the pharynx measured between the posterior pharyngeal wall and the surface of the tongue on a line parallel to the FH plane that runs through the tip of the epiglottis [3]. Cephalometric evaluation was done at T1, T2 and T3.

\section{Results}

In Seven patients (four females and three males), three patients with unilateral CLP and four patients with bilateral CLP underwent maxillary le fort I distraction osteogenesis using RED. The age ranged between (16 - 21) mean age 18.2 years. The range of maxillary advancement was between 8 - $15 \mathrm{~mm}$ (mean $9 \mathrm{~mm}$ ). All seven patients showed an improvement in esthetics and in the upper airway values on lateral cephalometric radiographs (Table 1). Five patients showed resolution of the mouth breathing. In all seven patients there was a clinically evident increase in the anteroposterior distance of the superior velopharynx (PPS) mean (6 mm) and middle velopharynx (SPPS) mean $(3.14 \mathrm{~mm})$ at T2. A small amount of reduction in these values were recorded at T3 PPS mean reduction $(1.28 \mathrm{~mm})$, SPPS mean reduction $(1.27 \mathrm{~mm})$. The inferior velopharynx (MPS) showed minimum increase at T2 mean $(2 \mathrm{~mm})$ and minimum reduction at T3 mean $(0.71 \mathrm{~mm})$.The oropharynx (IPS,EPS) showed increase in anteroposterior distance except in two patients at T2 mean IPS $2.71 \mathrm{~mm}$, EPS $2.14 \mathrm{~mm}$ and no change at $\mathrm{T} 3$. 
Table 1. Airway measurement changes after maxillary distraction osteogenesis.

\begin{tabular}{|c|c|c|c|c|c|c|c|c|c|c|}
\hline $\begin{array}{c}\text { Patient } \\
\text { no. }\end{array}$ & Sex & Age & Cleft type & $\begin{array}{c}\text { Amount of } \\
\text { maxillary } \\
\text { advancement (mm) }\end{array}$ & \multicolumn{2}{|c|}{$\begin{array}{l}\text { PPS } \\
(\mathrm{mm})\end{array}$} & $\begin{array}{l}\text { SPPS } \\
(\mathrm{mm})\end{array}$ & $\begin{array}{l}\text { MPS } \\
(\mathrm{mm})\end{array}$ & $\begin{array}{l}\text { IPS } \\
(\mathrm{mm})\end{array}$ & $\begin{array}{c}\text { EPS } \\
(\mathrm{mm})\end{array}$ \\
\hline 1 & F & $18 \mathrm{yr}$ & Unilateral & 12 & $\begin{array}{l}\text { T1 } \\
\text { T2 } \\
\text { T3 }\end{array}$ & $\begin{array}{l}25 \\
33 \\
32\end{array}$ & $\begin{array}{l}10 \\
14 \\
14\end{array}$ & $\begin{array}{c}8 \\
13 \\
12\end{array}$ & $\begin{array}{c}6 \\
10 \\
10\end{array}$ & $\begin{array}{l}5 \\
8 \\
8\end{array}$ \\
\hline 2 & $\mathrm{~F}$ & $16 \mathrm{yr}$ & unilateral & 8 & $\begin{array}{l}\text { T1 } \\
\text { T2 } \\
\text { T3 }\end{array}$ & $\begin{array}{l}28 \\
32 \\
30\end{array}$ & $\begin{array}{l}20 \\
23 \\
20\end{array}$ & $\begin{array}{l}19 \\
20 \\
20\end{array}$ & $\begin{array}{l}14 \\
14 \\
14\end{array}$ & $\begin{array}{l}15 \\
16 \\
15\end{array}$ \\
\hline 3 & M & $19 y r$ & unilateral & 16 & $\begin{array}{l}\text { T1 } \\
\text { T2 } \\
\text { T3 }\end{array}$ & $\begin{array}{l}13 \\
21 \\
20\end{array}$ & $\begin{array}{l}19 \\
20 \\
19\end{array}$ & $\begin{array}{c}9 \\
12 \\
11\end{array}$ & $\begin{array}{l}8 \\
9 \\
9\end{array}$ & $\begin{array}{l}10 \\
10 \\
10\end{array}$ \\
\hline 4 & F & $20 \mathrm{yr}$ & bilateral & 17 & $\begin{array}{l}\text { T1 } \\
\text { T2 } \\
\text { T3 }\end{array}$ & $\begin{array}{l}13 \\
19 \\
18\end{array}$ & $\begin{array}{l}12 \\
14 \\
12\end{array}$ & $\begin{array}{l}13 \\
13 \\
13\end{array}$ & $\begin{array}{c}8 \\
10 \\
10\end{array}$ & $\begin{array}{l}7 \\
9 \\
7\end{array}$ \\
\hline 5 & $\mathrm{~F}$ & $19 y r s$ & bilateral & 12 & $\begin{array}{l}\mathrm{T} 1 \\
\mathrm{~T} 2 \\
\mathrm{~T} 3\end{array}$ & $\begin{array}{l}21 \\
26 \\
25\end{array}$ & $\begin{array}{l}18 \\
22 \\
21\end{array}$ & $\begin{array}{l}24 \\
25 \\
24\end{array}$ & $\begin{array}{l}22 \\
25 \\
27\end{array}$ & $\begin{array}{l}11 \\
17 \\
15\end{array}$ \\
\hline 6 & M & $21 \mathrm{yr}$ & bilateral & 10 & $\begin{array}{l}\text { T1 } \\
\text { T2 } \\
\text { T3 }\end{array}$ & $\begin{array}{l}30 \\
34 \\
33\end{array}$ & $\begin{array}{l}11 \\
16 \\
15\end{array}$ & $\begin{array}{l}11 \\
13 \\
12\end{array}$ & $\begin{array}{c}8 \\
16 \\
17\end{array}$ & $\begin{array}{c}9 \\
17 \\
15\end{array}$ \\
\hline 7 & M & $20 \mathrm{yr}$ & Bilateral & 12 & $\begin{array}{l}\text { T1 } \\
\text { T2 } \\
\text { T3 }\end{array}$ & $\begin{array}{l}23 \\
30 \\
28\end{array}$ & $\begin{array}{l}20 \\
23 \\
22\end{array}$ & $\begin{array}{l}28 \\
30 \\
29\end{array}$ & $\begin{array}{l}20 \\
21 \\
21\end{array}$ & $\begin{array}{l}10 \\
12 \\
10\end{array}$ \\
\hline
\end{tabular}

*PPS; palatal pharyngeal space, SPPS; superior posterior pharyngeal space, MPS; middle pharyngeal space, IPS; inferior pharyngeal space, EPS; epiglottic pharyngeal space.

\section{Discussion}

How maxillary distraction osteogenesis alters the upper airway structure in cleft lip and palate patients is still a widely explored topic with many unanswered questions. Some reports stated that CLP patients with surgically repaired clefts had many dimensional and physiologic differences in their airway compared to non CLP patients [7] including nasal resistance which is $20 \%-30 \%$ higher than that in non CLP patients [8].

Results from this study indicate that maxillary advancement using distraction osteogenesis has lead to many changes in the upper airway. It showed an increase in palatal pharyngeal space (PPS) and superior posterior pharyngeal space (SPPS) in the immediate post distraction phase with a slight decrease in PPS during the follow up phase. This decrease in the PPS was found to be related to a relapse in maxillary position due to the pulling forces exerted by the surrounding soft tissues during the follow up period. One study reported a close link between the change in PNS position and the decrease in nasal resistance. It also noted that despite a slight decrease in the PPS, the increase in the upper airway dimension and the reduction in nasal resistance was still significant one year after maxillary distraction in CLP patients [3]. We have not evaluated the changes in nasal resistance with maxillary DO however all patients showed clinical improvement in airway and nasal breathing.

The change in upper airway structure and function was also noted in the acute change that followed orthognathic Le Fort I advancement [9]. However, with the gradual distraction of the maxilla the surrounding soft tissue envelope may have a better chance to accommodate to the changes than with the sudden change that happens with conventional Le Fort I advancement [3].

We also noted a change in the lower airway dimensions with a slight increase in the, middle pharyngeal space (MPS) and the inferior pharyngeal space (IPS). However, these changes were only evident in patients that presented initially with a steep mandibular plane angle due to a posterior vertical maxillary excess that seemed to lock the mandible in an inferior-posterior position. With the maxillary distraction, the mandible autorotated into a more anterior position leading to an increase in the lower airway dimensions. Other studies have reported some change in the lower airway after maxillary distraction, however this was not found to be significant [3]. In 
our study, the autorotation of the mandible did add to the clinical improvement in the airway.

One of the drawbacks of maxillary advancement in CLP patients is velopharyngeal (VPI) insufficiency especially in patients with existing VPI preoperatively. This can be explained by the increase in anterior-posterior dimensions of the nasopharynx. However, some studies suggested that the VPI will not be observed unless the maxillary advancement using conventional Le Fort I exceeds $10 \mathrm{~mm}$ [10] [11]. While Harada et al. suggested that VPI could be seen if maxillary distraction osteogenesis exceeds $15 \mathrm{~mm}$ [12]. Mochida et al. have reported that significant airway changes in CLP patients occur after a mean of $12.4 \mathrm{~mm}$ maxillary advancement [3]. In our study, the mean maxillary advancement using distraction osteogenesis was $9 \mathrm{~mm}$, despite that we did find some changes in airway measurements with a clinical improvement, however we did not evaluate the velopharyngeal function for any insufficiency as we only included a cephalometric study.

Some studies have suggested that adaptive changes in the soft palate morphology occur to preserve the oropharyngeal seal after maxillary advancement [13]-[15]. On the other side of the spectrum, one study reported no change in the morphology of the soft palate of CLP patients after maxillary distraction osteogenesis. However, it reported a change in the position of the soft palate rather than structure, with more anterior movement in midpoint of the soft palate than in the most inferior point [4]. In our study we evaluated the airway changes on lateral cephalometric radiographs. These measurements are only two dimensional however, the upper airway in a three dimensional space. A measurement of the upper airway volume would give a more accurate picture of these changes. Xu et al. measured the pharyngeal airway volume changes in syndromic patients who underwent midface distraction osteogenesis and found a 64\% enlargement after a mean of $20 \mathrm{~mm}$ advancement [16]. Jakobsone et al. reported a $13 \%$ to $21 \%$ increase in the nasopharyngeal airway dimensions with maxillary advancement [17]. A study was made to evaluate pharyngeal airway volume changes after maxillary and mandibular advancements using cone beam computed tomography. Results showed 37\% increase in the pharyngeal airway volume with maxillary advancement alone. This study also noted the advantages of the new cone-beam CT being an extremely effective noninvasive method for airway evaluation with low radiation [18]. Future studies to evaluate upper airway changes after maxillary distraction using cone beam CT would give valuable answers to valuable questions like how maxillary DO changes the upper airway in CLP patients.

In our study we have demonstrated the upper airway changes that occurred after maxillary DO in CLP patients. We have found a clinically evident increase in the anteroposterior distance of the superior velopharynx (PPS) and middle velopharynx (SPPS) with less increase in the inferior velopharynx (MPS) and the oropharynx (IPS, EPS). The draw backs of this study is that lateral cephalometric records were used to measure airway changes as this was a retrospective study and lateral cephelomtric radiographs do not give a three dimensional evaluation for the airway. Although all patients reported clinical improvement in breathing during sleep, future studies to evaluate upper airway changes with volumetric measures using cone beam CT would help unveil the mystery of airway changes in CLP patients after maxillary DO.

\section{References}

[1] Polley, J. and Figueroa, A. (1997) Management of Severe Maxillary Deficiency in Childhood and Adolescence through Distraction Osteogenesis with an External Adjustable Rigid Distraction Device. Journal of Craniofacial Surgery, 8, 181-185. http://dx.doi.org/10.1097/00001665-199705000-00008

[2] Rachmiel, A., Aizebud, D., Ardekian, L., et al. (1999) Surgically-Assisted Orthopaedic Protraction of the Maxilla in Cleft Lip and Palate Patients. International Journal of Oral and Maxillofacial Surgery, 28, 9-14 http://dx.doi.org/10.1016/S0901-5027(99)80668-7

[3] Mochida, M., Ono, T., Saito, K., Tsuiki, S. and Ohyama, K. (2004) Effects of Maxillary Distraction Osteogenesis on the Upper-Airway Size and Nasal Resistance in Subjects with Cleft Lip and Palate. Orthodontics \& Craniofacial Research, 7, 189-197. http://dx.doi.org/10.1111/j.1601-6343.2004.00300.x

[4] Aksu, M., Taner, T., Sahin-Veske, P., Kocadereli, I., et al. (2012) Pharyngeal Airway Changes Associated with Maxillary Distraction Osteogenesis in Adult Cleft Lip and Palate Patients. Journal of Oral and Maxillofacial Surgery, 70, 133-140. http://dx.doi.org/10.1016/j.joms.2011.10.009

[5] Wiltfang, J., Hirschfelder, U., Neukam, F. and Kessler, P. (2002) Long-Term Results of Distraction Osteogenesis of the Maxilla and Midface. British Journal of Oral and Maxillofacial Surgery, 40, 473. http://dx.doi.org/10.1016/S0266435602002474

[6] Figueroa, A., Polley, J., Fried, H. and Ko, E.W. (2004) Long-Term Skeletal Stability after Maxillary Advancement with Distraction Osteogenesis Using a Rigid External Distraction Device in Cleft Maxillary Deformities. Plastic and Reconstructive Surgery, 114, 1382 (discussion 1393). 
[7] Hairfield, W. and Warren, D. (1989) Dimensions of the Cleft Nasal Airway in Adults: A Comparison with Subjects without Cleft. The Cleft Palate Journal, 26, 9-13.

[8] Warren, D., Duany, L. and Fischer, N. (1969) Nasal Pathway Resistance in Normal and Cleft and Lip and Palate Subjects. The Cleft Palate Journal, 6, 134-140.

[9] Jakobsone, G., Stenvik, A. and Espeland, L. (2011) The Effect of Maxillary Advancement and Impaction on the Upper Airway after Bimaxillary Surgery to Correct Class III Malocclusion. American Journal of Orthodontics and Dentofacial Orthopedics, 139, e369. http://dx.doi.org/10.1016/j.ajodo.2010.07.022

[10] Witzel, M. and Munro, I. (1977) Velopharyngeal Insufficiency after Maxillary Advancement. The Cleft Palate Journal, 14, 176.

[11] Maegawa, J., Sells, R. and David, D. (1998) Speech Changes after Maxillary Advancement in 40 Cleft Lip and Palate Patients. Journal of Craniofacial Surgery, 9, 177. http://dx.doi.org/10.1097/00001665-199803000-00017

[12] Harada, K., Ishii, Y., Ishii, M., et al. (2002) Effect of Maxillary Distraction Osteogenesis on Velopharyngeal Function: A Pilot Study. Oral Surgery, Oral Medicine, Oral Pathology, Oral Radiology, and Endodontology, 93, 538. http://dx.doi.org/10.1067/moe.2002.123827

[13] Heliövaara, A., Hukki, J., Ranta, R., et al. (2004) Cephalometric Pharyngeal Changes after Le Fort I Osteotomy in Different Types of Clefts. Scandinavian Journal of Plastic and Reconstructive Surgery and Hand Surgery, 38, 5-10. http://dx.doi.org/10.1080/02844310310009537

[14] Turnbull, N. and Battagel, J. (2000) The Effects of Orthognathic Surgery on Pharyngeal Airway Dimensions and Quality of Sleep. Journal of Orthodontics, 27, 235-247.

[15] Schendel, S., Oeschlaeger, M., Wolford, L. and Epker, B.N. (1979) Velopharyngeal Anatomy and Maxillary Advancement. Journal of Maxillofacial Surgery, 7, 116-124. http://dx.doi.org/10.1016/S0301-0503(79)80023-5

[16] Xu, H., Yu, Z. and Mu, X. (2009) The Assessment of Midface Distraction Osteogenesis in Treatment of Upper Airway Obstruction. The Journal of Craniofacial Surgery, 20, 1876-1881.

[17] Jakobsone, G., Stenvik, A. and Espeland, L. (2011) The Effect of Maxillary Advancement and Impaction on the Upper Airway after Bimaxillary Surgery to Correct Class III Malocclusion. American Journal of Orthodontics and Dentofacial Orthopedics, 139, e369. http://dx.doi.org/10.1016/j.ajodo.2010.07.022

[18] Hernández-Alfaro, F., Guijarro-Martínez, R. and Mareque-Bueno, J. (2011) Effect of Mono- and Bimaxillary Advancement on Pharyngeal Airway Volume: Cone-Beam Computed Tomography Evaluation. Journal of Oral and Maxillofacial Surgery, 69, e395-e400. http://dx.doi.org/10.1016/j.joms.2011.02.138 